\title{
A IMPORTÂNCIA DOS JOGOS PARA O DESENVOLVIMENTO E APRENDIZAGEM DA CRIANÇA DE SETE A DOZE ANOS
}

Isabela Samogim Santos, Carla Plantier Message, Cecília Maria Prates de Freitas, Carmem Lúcia Dias.

Universidade do Oeste Paulista - UNOESTE, Mestrado em Educação, Presidente Prudente, SP. E-mail: isamogim@hotmail.com

\section{RESUMO}

O presente artigo tem como objetivo ressaltar a importância dos jogos para o desenvolvimento e aprendizagem da criança de sete a doze anos. As pesquisadoras propuseram-se a relacionar o estágio das operações concretas; que é um dos quatro estágios que menciona o autor Piaget com os jogos como ferramenta no ensino-aprendizagem infantil. Nesse estágio que tem como período dos 7 aos 12 anos das crianças, os jogos podem contribuir significativamente para a aprendizagem, o desenvolvimento da inteligência e na construção do conhecimento científico. Para tal objetivo, utilizamos como metodologia a pesquisa bibliográfica onde autores dessa área propõem uma discussão acerca de questões pertinentes ao uso de jogos para o desenvolvimento da aprendizagem e autonomia infantil. Portanto, conclui-se que a utilização de certos jogos e brincadeiras como facilitadores da aprendizagem na educação infantil, é sem dúvida, a solução para se obter resultados positivos no processo de ensino-aprendizagem das crianças. Palavras- chave: Jogos. Desenvolvimento e aprendizagem. Autonomia moral e intelectual. Educação infantil.

\section{THE GAMES OF IMPORTANCE FOR DEVELOPMENT AND LEARNING THE CHILD SEVEN TO TWELVE YEARS OLD}

\begin{abstract}
This paper discuss the importance of highlighting the games for development and learning the child seven to twelve years old. The researchers relate the stage of concrete operations; one of the four stages that mentions the author Piaget with the games as a tool for education and children's learning. At this stage whose period of 7 to 12 years old children's, games can contribute significantly to the learning, the intelligence development and construction of scientific knowledge. For this purpose, we use as methodology the literature where authors of this area offers a discussion of relevant issues related to the use of games for learning and development of children's autonomy. So, it is conclued that the use of certain games and jokes as facilitators in the learning, early childhood education, certainly is the solution to obtain positive results in the teaching and learning process of children.
\end{abstract}

Keywords: Games. Development and learning. Moral and intellectual autonomy. Child education. 


\section{INTRODUÇÃO}

O processo de ensino e aprendizagem através de práticas pedagógicas elaboradas pelo professor tem como objetivo despertar o interesse e estimular a participação das crianças nas atividades construtivistas e socializadoras, propiciando experiências nas quais as crianças vão adquirir conhecimento de forma significativa.

Para que os alunos adquiram o conhecimento nesse processo, o professor deve utilizar de metodologias adequadas às necessidades de cada aluno, considerando idade e condições cognitivas.

A educação deve favorecer a construção de sujeitos autônomos e críticos. Considerando esses objetivos, devemos buscar conhecer as circunstâncias e ambientes que favoreçam a construção tanto da autonomia moral quanto intelectual.

Alguns estudiosos indicam que um dos momentos propícios para o desenvolvimento da autonomia infantil é o jogo, uma vez que este envolve a construção de regras, negociações e concentrações por parte dos participantes.

Piaget (1975b) buscou compreender nos jogos, como as crianças entendiam a formação de regras, e como isso interferia em seu desenvolvimento cognitivo e moral. Esses estudos vieram indicar que o desenvolvimento de estruturas lógicas e de moralidade, poderia ser favorecido quando o ambiente escolar fosse facilitador, promovendo a reflexão do sujeito diante dos problemas lógicos e dilemas morais.

Na prática do uso de jogos é possível trabalhar com o limite, o respeito, a disciplina, o diálogo e valores éticos, tornando a vida social mais justa. Nos jogos em grupo a cooperação promove, através do lúdico, o trabalho em equipe, habilidade de compartilhar, de lidar com regras, de liderar e ser liderado, levando a criança ao sucesso em seu relacionamento social, cooperativo e participativo.

Nesse artigo as pesquisadoras propuseram-se a relacionar o estágio das operações concretas; início da lógica e dos sentimentos morais e sociais de cooperação (PETRUCl, 20012002), um dos quatro estágios que menciona o autor Piaget com os jogos como ferramenta no ensino-aprendizagem infantil. Nesse estágio que tem como período dos sete aos 12 anos das crianças, os jogos podem contribuir significativamente para a aprendizagem.

Sendo assim, o objetivo deste artigo é fazer uma explanação sobre a aplicação de jogos como ferramenta estimuladora, facilitadora e enriquecedora da aprendizagem infantil, auxiliando de maneira prazerosa o processo de ensino.

\section{METODOLOGIA}

Para a realização deste estudo foram utilizados procedimentos metodológicos próprios das pesquisas bibliográficas. Através da investigação bibliográfica, considerada por Vergara (1998, p. 46), como aquela que "é estudo sistematizado desenvolvido com base em material publicado em livros, revistas, jornais, redes eletrônicas, isto é, material acessível ao público em geral", com base na qual foi empreendida a revisão de literatura que possibilitou a fundamentação teórica sobre a temática do estudo.

\section{DISCUSSÃO}

\section{A APRENDIZAGEM}

A aprendizagem é um sistema complexo. Não engloba somente o processo de aquisição de conhecimentos, conteúdos ou informações, mas também a assimilação e a apreensão desses conhecimentos, conteúdos e informações, a fim de tornar o aluno em seres críticos (PILETTI; ROSSATO, 2013).

A aprendizagem não é um processo passivo, sua característica mais importante é a atividade daquele que aprende. Portanto a aprendizagem só se faz através da participação do aprendiz. 
De acordo com Rousseau - filósofo (1712-1778) - a aprendizagem é adquirida através das experiências, por isso devemos deixar que a criança viva cada fazer no seu devido tempo. Compreende-se que a educação é um processo natural devendo ser respeitada o desenvolvimento da criança em suas fases. Como afirma Rousseau (apud COURA, 2004, p.72) "amai a infância, favorecei as brincadeiras, seus prazeres, seu amável instinto."

Contribuindo, Vygotsky (1988) coloca que aprendizado e desenvolvimento estão interrelacionados desde o primeiro dia de vida. Assim, é fácil concluir que o aprendizado da criança começa muito antes de ela frequentar a escola.

Para se adquirir o aprendizado é muito importante que o aluno tenha desejo em aprender. Tenha motivação, estímulo para o aprendizado e esta motivação pode ser incentivada pelo professor através de recursos atrativos, utilizando a linguagem do aluno com intuito de enriquecer seus conhecimentos. Uma forma de tornar o saber prazeroso é inserindo jogos e brincadeiras no planejamento diário.

Para Piaget (1975b), o jogo é essencial para contribuir no processo de aprendizagem. Ao lançar um jogo desconhecido, o aluno entrará em conflito cognitivo. No entanto, logo ao tomar conhecimento e compreender melhor as ideias, este estará assimilando e acomodando o novo conhecimento.

\section{O JOGO}

O jogo possibilita uma forma harmoniosa, descontraída e alegre para a busca de conhecimentos. Todo jogo leva a aprendizagem, não somente dos conteúdos escolares, mas também se aprende a socialização, coordenação motora, criatividade, autonomia, etc. Todos os jogos têm uma intencionalidade, e com eles pode-se integrar professor e alunos, e de maneira lúdica os alunos aprendem a partilhar, seguir regras e socializar-se.

De acordo com Viana, Teixeira e Vieira (1989) o jogo é uma atividade que agrada e estimula os seus participantes. Sendo uma importante ferramenta no desenvolvimento das aulas. Uma aula onde se utiliza dessa ferramenta é animada, divertida e participada.

Já para Vygotsky (1988), o brinquedo ajudará a desenvolver uma diferenciação entre a ação e o significado. A criança com o seu evoluir passa a estabelecer relação entre o seu brincar e a ideia que se tem dele, deixando de ser dependente de estímulos físicos. O brincar relaciona-se com a aprendizagem permitindo a criança um enfrentamento das dificuldades do processo ensinoaprendizagem.

Os jogos precisam ser vistos como algo para facilitar o ensino aprendizagem, podendo ser um motivador para a criança que aprende da forma não tradicional, que por muitos anos foi a única forma de ensino aplicada nas escolas. Assim, o jogo é visto como um estimulador, uma novidade para a criança que aprende brincando.

Piaget (1975b) encontrou quatro estágios na maneira como as crianças jogam:

- Jogo motor individual, onde a criança joga sozinha, fazendo uma infinidade de coisas que não podem ser classificadas como um jogo;

- Jogo egocêntrico, aqui as crianças costumam imitar os mais velhos, mas jogam sozinhas, sem se preocupar em ganhar, porque nessa fase o que importa são elas, por isso o egocentrismo;

- Cooperação incipiente começam as competições, a criança tenta vencer, é nesse caso que as crianças veem a necessidade de cooperação para chegar num resultado;

- Codificação de regras, que tem como objetivo ensinar às crianças a autonomia, sem precisar ensinar-lhes como jogar. Assim, com regras a criança desenvolve características sociais, moral, cognitiva, política e emocional. 


\section{FASE OPERATÓRIA}

No período das operações concretas o pensamento das crianças, passa do particular para o real, a criança fica mais concentrada, assim os jogos de regras, onde a criança consegue autorregular-se são indicados nessa fase. Os jogos podem ser realizados com a finalidade de pontuação, para gerar um campeão ou não, tudo dependerá da maturidade das crianças participantes.

Segundo Piaget (1975a) é na fase das operações concretas (dos 7 aos 11 anos aproximadamente) que as crianças aprendem as regras dos jogos e jogam em grupos. Esta é a fase dos jogos de regras como futebol, damas, etc. , na fase adiante os 7 e 11-12 anos, começam a aparecer com mais frequência desenhos, trabalhos manuais, construções com materiais didáticos, representações. Piaget não considera este tipo de jogo como sendo um segundo estágio e sim como estando entre os jogos simbólicos e de regras.

O teórico fala ainda que o jogo de regras começa a se manifestar por volta dos cinco anos, mas desenvolve-se principalmente dos 7 aos 12 anos. Este tipo de jogo continua durante toda a vida do indivíduo (esportes, trabalho, jogos de xadrez, baralho, RPG (Role Playing Game), etc.

O jogo de regra pressupõe a existência de parceiros e um conjunto de obrigações (as regras), o que lhe confere um caráter eminentemente social. Este jogo aparece quando a criança abandona a fase egocêntrica possibilitando desenvolver os relacionamentos afetivo-sociais, a autonomia moral e intelectual.

\section{CONCLUSÃO}

Hoje sabe-se que a criança aprende brincando. O jogo, para a criança, é o exercício e a preparação para a vida adulta. A utilização de certos jogos e brincadeiras como facilitadores na aprendizagem, na educação infantil, são sem dúvida, a solução para se obter resultados positivos no processo de ensino - aprendizagem das crianças.

Os jogos com regras conseguem imprimir na criança o aprendizado do raciocínio lógico, questionar erros e acertos, pensar em hipóteses, controlar condições favoráveis, realizar medição de risco, pesquisar, interpretar, tomar decisões, entre outros. O jogo é capaz se bem aplicado, a ensinar o aluno àquilo que muitas vezes ele demoraria mais tempo para aprender da maneira tradicional, pois aprende brincando, de forma lúdica, sem a pressão de aprender normalmente existente dentro das salas de aula que seguem a forma tradicional de ensino.

A criança, através dojogo, faz suas próprias descobertas, testa seus limites, aprende regras básicas de convivência e desenvolve o emocional e o cognitivo. A criança aprende brincando, pois a brincadeira é algo sem "compromisso" que se realiza naturalmente, sem cobranças, fazendo-se necessária a inclusão de jogos como ferramenta pedagógica para profissionais e educadores que trabalham com a educação infantil.

\section{REFERÊNCIAS}

COURA, A.S. Princípios fundamentais da educação em Rousseau. 2005. Universidade Federal de Campina Grande. Anais do II Colóquio Rousseau.

PIAGET, J. A equilibração das estruturas cognitivas. Rio de Janeiro: Zahar, 1975a.

PIAGET, J. A formação do símbolo na criança: imitação, jogo e sonho, imagem e representação. 2.ed. Rio de janeiro: Zahar, 1975b.

PILETTI, N.; ROSSATO, M. Psicologia da Aprendizagem - da Teoria do condicionamento ao construtivismo. São Paulo: Contexto, 2013. 
PETRUCl, M. das G. R. M. Psicogenética de Jean Piaget: algumas implicações didáticas. Pedagogia Cidadã/UNESP, 2001-2002, mimeo.

VERGARA, S. C. Projetos e relatórios de pesquisa em administração. São Paulo: Atlas, 1998.

VIANA, J. P.; TEIXEIRA, P.; VIEIRA, R.. Educação e Matemática. Revista da Associação de Professores de Matemática, 1989.

VYGOTSKY, L. S. Aprendizagem e desenvolvimento intelectual na idade escolar. In: VIGOTSKY, L. S.; LURIA, A. R.; LEONTIEV, A. N. Linguagem, desenvolvimento e aprendizagem. Tradução de Maria da Penha Villalobos. 2. ed. São Paulo: Ícone, 1988. p. 103-117. 